Communication

\title{
A Simplified and Robust Activation Procedure of Glass Surfaces for Printing Proteins and Subcellular Micropatterning Experiments
}

\author{
Tina Karimian $^{1}$, Roland Hager ${ }^{1}\left(\mathbb{D}\right.$, Andreas Karner ${ }^{2} \mathbb{D}$, Julian Weghuber ${ }^{1,3} \mathbb{D}$ and Peter Lanzerstorfer ${ }^{1, *} \mathbb{D}$ \\ 1 School of Engineering, University of Applied Sciences Upper Austria, 4600 Wels, Austria; \\ tina.karimian@fh-wels.at (T.K.); roland.hager@fh-wels.at (R.H.); julian.weghuber@fh-wels.at (J.W.) \\ 2 School of Engineering, University of Applied Sciences Upper Austria, 4020 Linz, Austria; \\ andreas.karner@fh-linz.at \\ 3 FFoQSI GmbH, Austrian Competence Center for Feed and Food Quality, Safety \& Innovation, \\ 3430 Tulln, Austria \\ * Correspondence: peter.lanzerstorfer@fh-wels.at; Tel.: +43-50804-44402
}

Citation: Karimian, T.; Hager, R.; Karner, A.; Weghuber, J.; Lanzerstorfer, P. A Simplified and Robust Activation Procedure of Glass Surfaces for Printing Proteins and Subcellular Micropatterning Experiments. Biosensors 2022, 12, 140. https://doi.org/10.3390/ bios12030140

Received: 2 February 2022 Accepted: 22 February 2022 Published: 25 February 2022

Publisher's Note: MDPI stays neutral with regard to jurisdictional claims in published maps and institutional affiliations.

Copyright: (C) 2022 by the authors. Licensee MDPI, Basel, Switzerland. This article is an open access article distributed under the terms and conditions of the Creative Commons Attribution (CC BY) license (https:// creativecommons.org/licenses/by/ $4.0 /)$.

\begin{abstract}
Depositing biomolecule micropatterns on solid substrates via microcontact printing $(\mu \mathrm{CP})$ usually requires complex chemical substrate modifications to initially create reactive surface groups. Here, we present a simplified activation procedure for untreated solid substrates based on a commercial polymer metal ion coating (AnteoBind ${ }^{\mathrm{TM}}$ Biosensor reagent) that allows for direct $\mu \mathrm{CP}$ and the strong attachment of proteins via avidity binding. In proof-of-concept experiments, we identified the optimum working concentrations of the surface coating, characterized the specificity of protein binding and demonstrated the suitability of this approach by subcellular micropatterning experiments in living cells. Altogether, this method represents a significant enhancement and simplification of existing $\mu \mathrm{CP}$ procedures and further increases the accessibility of protein micropatterning for cell biological research questions.
\end{abstract}

Keywords: micropatterning; micro-contact printing; fluorescence microscopy; live cell analysis

\section{Introduction}

Depositing biomolecules onto solid substrates in regular 2D patterns with micrometer resolution, also known as molecular printing or, more commonly, as protein micropatterning, has found widespread use in academic laboratories, and multiple applications for biomedical and cell biological research have emerged [1-8]. In this regard, many different methodologies have been developed in the recent years, whereas the fabrication of biomolecule micropatterned (and even nanopatterned) solid substrates is mainly depending on the intended application and available lab infrastructure. Basically, those techniques can be classified into direct and indirect deposition strategies.

The indirect strategies include methodologies such as the widely used photolithography [9], laser microablation [10], colloidal lithography [11], di-block copolymer micelle nanolithography [12] or di-block copolymer self-assembly [13]. Direct protein deposition can be realized by approaches such as dip-pen lithography (DPL) [14], microchannel cantilever spotting $(\mu \mathrm{CS})$ [15], polymer pen lithography (PPL) [16], microfluidic patterning [17], fluidic force microscopy (FluidFM) [18] and soft lithography via microcontact printing $(\mu \mathrm{CP})$ [19]. Within those tools, $\mu \mathrm{CP}$ (especially in combination with poly(dimethylsiloxane) (PDMS) stamps) is the most convenient and widely used method for protein micropatterning. Protein patterning by $\mu \mathrm{CP}$ provides unique features compared with all other sophisticated patterning technologies as it is: (i) highly reproducible and robust, (ii) easy to perform, (iii) extremely fast, (iv) modularly expandable (with respect to feature size and printed protein), (v) comparatively cheap, and (vi) independent of special lab equipment. 
Variations, core advantages and methodological limitations of $\mu \mathrm{CP}$ have been reported and discussed in various recent studies [17,19-23].

Though comparatively simple in implementation and execution, $\mu \mathrm{CP}$ still requires complex chemical modifications of the substrate to increase surface energy and to generate functional groups (e.g., carboxyl, amine, hydroxyl or epoxy groups) for the direct covalent attachment of biomolecules. Functional chemical moieties are typically introduced using methodologies such as plasma treatment, UV irradiation and monolayer selfassembly [24-26]. Alternatively, customized substrates carrying a wide range of functional coating chemistries are available from various companies. However, a direct company supply is often associated with long waiting periods, high purchase quantities and variations in surface quality, resulting in rather expensive substrates for subsequent $\mu \mathrm{CP}$ and intended applications.

Most recently, a nanocontact printing approach for the generation of protein nanopatterns ( $80 \mathrm{~nm}$ feature size) on polymer-metal ion-coated substrates was reported using a Mix\&Go surface chemistry (AnteoBind ${ }^{\mathrm{TM}}$ Biosensor reagent) and a two-layer stamp architecture (X-PDMS) [27]. The applied polymer-metal ion coating does not react with water and allows for the strong attachment of proteins via avidity binding. In this regard, such coated surfaces have been reported for various different applications, ranging from electrochemical immunosensors [28-30], antibody immunoassay [31], amperometric immunoassay [32] and extracellular vesicle detection [33]. Furthermore, metal-polyphenol coatings and micropatterns have been recently reported for simple biomolecule binding [34] and platelet adhesion [35].

Here, we present an extension of the $\mu \mathrm{CP}$ method for the simplified and robust fabrication of 2D protein micropatterns. We exemplify our approach by creating microstructured streptavidin- and antibody-patterned surfaces with feature sizes of $3 \mu \mathrm{m}$. We provide a detailed protocol for the implementation of the Mix\&Go surface chemistry for glass substrates, identify optimum working concentrations and demonstrate the biocompatibility by subcellular micropatterning experiments in living cells.

\section{Materials and Methods}

\subsection{Reagents and DNA Constructs}

Bovine serum albumin, streptavidin, polydimethylsiloxane (PDMS, SYLGARD ${ }^{\circledR} 184$ ), AnteoBind ${ }^{\mathrm{TM}}$ Biosensor reagent, FITC-conjugated avidin, and Tween-20 were purchased from Sigma-Aldrich (Schnelldorf, Germany). 2-(N-morpholino)ethanesulfonic acid (MES) was purchased from Carl Roth (Karlsruhe, Germany). Cy5-conjugated streptavidin and Zenon IgG Labeling Kit was obtained from ThermoFisher Scientific (Waltham, MA, USA). BSA-Cy 5 was purchased from Protein Mods (Madison, WI, USA). Biotinylated antibodies were obtained from Antibodies Online (Herford, Germany). Ninety-six-well plastic castings were obtained from Greiner Bio-One GmbH (Frickenhausen, Germany). NEXTERION glass coverslips (110 mm $\times 74 \mathrm{~mm}, 175 \pm 20 \mu \mathrm{m}$ thickness) were from Schott GmbH (Jena, Germany). Biotin-labeled human fibrinogen was purchased from Innovative Research (Novi, MI, USA).

\subsection{Glass Substrate Activation}

Glass coverslips were initially cleaned with $\mathrm{EtOH}$ and $\mathrm{dH}_{2} \mathrm{O}$, dried under a stream of air (or nitrogen) and incubated with $15 \mathrm{~mL}$ AnteoBind ${ }^{\mathrm{TM}}$ Biosensor reagent (with indicated concentrations) for $30 \mathrm{~min}$. Subsequently, excess reagent was carefully removed from the surface and the coverslip was again washed with $\mathrm{dH}_{2} \mathrm{O}$ and dried. Coated glass substrates were immediately used for $\mu \mathrm{CP}$.

\subsection{Preparation of Large-Area PDMS Stamps}

A PDMS prepolymer was mixed in a ratio of 10:1 (w/w, precursor:curing agent) and degassed in a desiccator for $30 \mathrm{~min}$ to remove air bubbles. The PDMS mixture was then poured on a silanized wafer (Delta Mask, Enschede, The Netherlands) containing an array 
of round-shaped pillars with a feature size and depth of three micrometers. The mixture on the wafer was degassed again, cured for $2 \mathrm{~h}$ at $80^{\circ} \mathrm{C}$ and, finally, peeled off from the wafer for $\mu \mathrm{CP}$.

\subsection{Preparation of Protein Micropatterns by $\mu \mathrm{CP}$}

Prior to $\mu \mathrm{CP}$, the PDMS stamp was washed with $\mathrm{EtOH}$ and $\mathrm{dH}_{2} \mathrm{O}$, followed by drying under a stream of air (or nitrogen). The stamp was then incubated for $1 \mathrm{~h}$ at room temperature with a BSA or BSA-Cy5 solution (with indicated concentrations) in the dark. Subsequently, the stamp was washed with $\mathrm{PBS}$ and $\mathrm{dH}_{2} \mathrm{O}$, dried again, and placed by its own weight upside down on the activated glass substrate. The stamp was peeled off after 30 min of incubation and the BSA-patterned substrate was bonded to a 96-well plastic casting using an adhesive tape (3M, laser cut to 96-well layout). The resulting reaction chambers were subsequently incubated with $70 \mu \mathrm{L}$ streptavidin or streptavidinCy5 solution (50 $\mu \mathrm{g} / \mathrm{mL}$ in $25 \mathrm{mM}$ MES, pH 6) for $20 \mathrm{~min}$ at room temperature. Proteinpatterned surfaces were washed three times with PBST (pH 7.4 with $0.05 \%$ Tween-20 $(v / v)$ ) and imaged by fluorescence microscopy.

\subsection{Cell Culture and Transfection}

HeLa cells were obtained from ATCC, cultured in RPMI medium supplemented with 10\% FBS and 1\% penicillin/streptomycin (all PAN-Biotech $\mathrm{GmbH}$, Aidenbach, Germany) and grown at $37{ }^{\circ} \mathrm{C}$ in a humidified incubator with $5 \% \mathrm{CO}_{2}$. Cells were transiently transfected with fluorescent-fusion constructs using jetOPTIMUS DNA transfection reagent (Polyplus transfection, Illkirch, France), according to the manufacturer's protocol. A total of 24-48 h after transfection, cells were used for subcellular micropatterning experiments.

\subsection{Subcellular Micropatterning Experiments in Living Cells}

For live cell micropatterning experiments, streptavidin-patterned surfaces were further modified by incubating biotinylated bait antibodies $(10 \mu \mathrm{g} / \mathrm{mL}$, as indicated $)$ for another $20 \mathrm{~min}$ at room temperature. Antibody-functionalized chambers were finally washed with PBS (three times) and bait-protein expressing cells were grown on the patterned surfaces for at least $3-4 \mathrm{~h}$ prior to fluorescence imaging.

\subsection{Fluorescence Microscopy}

TIRF microscopy was carried out on a microscopy set-up as used in a previous study [36].

\subsection{Atomic Force Microscopy}

AFM imaging was performed at room temperature on a JPK NanoWizard 4 (Bruker, MA, USA) operated in tapping mode and using MSNL cantilevers (Bruker, MA, USA). Open source Gwyddion software (version 2.60, http: / / gwyddion.net/) was used for image processing [37].

\subsection{Image Analysis and Statistical Evaluation}

Initial imaging recording was supported by the Olympus XcellenceRT software package (version 1.1). Images were exported as TIFF frames and fluorescence contrast analysis was performed using the Spotty framework (version 3.7, https: / / bioinformatics.fhhagenberg.at/bin_typo3/htdocs/fileadmin/user_upload/Downloads/spotty.html) as described previously [36,38].

For significance testing, an unpaired t-test was used to compare two experimental groups, whereas comparison of more than two different groups was performed using one-way ANOVA, which was followed by Tukey's multiple comparisons test. All data transformation and statistical comparisons were carried out in GraphPad Prism software (version 9). 


\section{Results and Discussion}

\subsection{Simplified Procedure for the Fabrication of Protein Micropatterned Glass Substrates}

The principle of our surface preparation is shown in Figure 1A-F, exemplified by large-area surface patterning for increased experimental throughput. A simplified scheme of the $\mu \mathrm{CP}$ process is depicted in Figure S1. Following this workflow, the micron-scale protein-patterned glass substrate was generated by printing a biocompatible and chemically stable background protein possessing good surface passivation properties onto the AnteoBind ${ }^{\mathrm{TM}}$ precoated glass. As shown in our previous work $[36,39]$, BSA meets those demands and was used throughout this study. AFM images of the BSA grid revealed an almost defect-free surface passivation (Figure $1 \mathrm{H}$ ), with an average height of the printed BSA of $\sim 3-4 \mathrm{~nm}$, which corresponds to a BSA monolayer formed upon $\mu \mathrm{CP}$. After $\mu \mathrm{CP}$, the pre-patterned glass substrate was manually bonded to a multi-well plastic casting resulting in a modular ready-to-use micropatterning platform. The unblocked $3 \mu \mathrm{m}$ patterns were subsequently filled with streptavidin, followed by the incubation of biotinylated antibodies (Figure 1G, TIRF microscopy images of BSA-Cy5 grid and FITC-labeled antibodies are shown for illustration) and the seeding of cells expressing fluorescence fusion proteins of interest. The antibody will bind to the extracellular domain of a membrane-anchored protein (e.g., receptor; also termed as bait protein), resulting in a rearrangement of the bait in the cell membrane into an ordered array according to the micron-scale antibody pattern. We and others have used similar assays (although with methodological variations) to investigate cell signaling and cell membrane receptor-dependent protein-protein interactions (PPIs) [40-47]. Most recently, we further developed the approach enabling the subcellular dynamic immunopatterning of cytosolic protein complexes [36]. The use of this platform is not only restricted to antibodies, rather, it enables fast and easy modular surface functionalization using different bait-capturing biomolecules such as specific ligands [46], ligand-decorated multi-scale origami structures [39] and multivalent chelator nanotools [47].

By adapting our micropatterning assay to the described polymer-metal ion coating, we attempted to create very stable and active surfaces, which are capable of binding many classes of biomolecules and serve as biointerfaces for subcellular micropatterning experiments in living cells.

\subsection{Characterization of Protein Binding on Micropatterned Substrates}

To elaborate on the applicability of the polymer-metal ion coating for protein micropatterning via $\mu \mathrm{CP}$, we functionalized untreated glass coverslips using the procedure as described in Figure 1. In a first step, we identified optimum working concentrations of the AnteoBind ${ }^{\mathrm{TM}}$ coating reagent (Figure $2 \mathrm{~A}, \mathrm{C}$ ). For this purpose, glass substrates were covered by different concentrations of the polymer-metal ion reagent followed by $\mu \mathrm{CP}$ of the micron-scale BSA grid $(5 \mathrm{mg} / \mathrm{mL})$ and subsequent incubation of STA-Cy5, whereas the quality of BSA transfer was evaluated by means of STA-Cy5 fluorescence signal. Figure 2A shows representative TIRF microscopy images of STA-Cy5-patterned glass surfaces that were precoated with indicated AnteoBind ${ }^{\mathrm{TM}}$ reagent concentrations. Representative line profiles of the respective STA-Cy5 signals are shown in Figure 2C. Non-specific binding of STA-Cy5 in BSA-patterned grid areas was comparably reduced to a minimum for surfaces coated with pure reagent down to a dilution step of 1:20. However, the highest levels of specific STA-Cy5 enrichment inside the non-passivated patterns were detected on substrates with pure AnteoBind ${ }^{\mathrm{TM}}$ reagent coating, followed by slightly reduced fluorescence signals down to a concentration of a 1:20 dilution. AnteoBind ${ }^{\mathrm{TM}}$ reagent concentrations below 1:20 delivered significantly lower levels of STA-Cy5 patterning, whereas the highest background signal in combination with the lowest STA-Cy5 signal was obtained for glass surfaces without polymer-metal ion coating. Indeed, biomolecule printing and binding without loss of functionality onto untreated glass coverslips has been reported in various studies $[44,48,49]$. However, exact mechanisms of protein binding on unmodified glass have not been fully understood so far and are mainly dependent on the surface properties 
themselves, as well as on the adsorption protein [50]. Most importantly, attaching proteins to rather inactive surfaces, such as plane glass, might lead to lower surface passivation, increased unspecific binding, decreased specific binding of the protein of interest, eventual loss of protein function or reduced binding capabilities, and unstable biointerfaces with shortened storage life. Furthermore, it is not entirely clear what holds the polymer-metal ion complex on the bare glass surface. However, it was previously shown that such metal complexes can bind to plain non-irradiated polystyrene surfaces, as well as to untreated cyclic olefin copolymer substrates [31,51]. What is noteworthy, is that untreated glass surfaces were also reported to possess anionic surface properties [52], therefore being able to bind cationic biomolecules, as it might also be the case for the positively charged polymermetal ion complex. Hence, we speculate that the 'adsorption forces' are a mixture of ionic interactions and hydrogen bonds due to surface charges and impurities (e.g., presence of other metal ions, surface oxygen groups, etc.). Eventually, simple diffusion into the porous glass structure might also be a possible explanation.

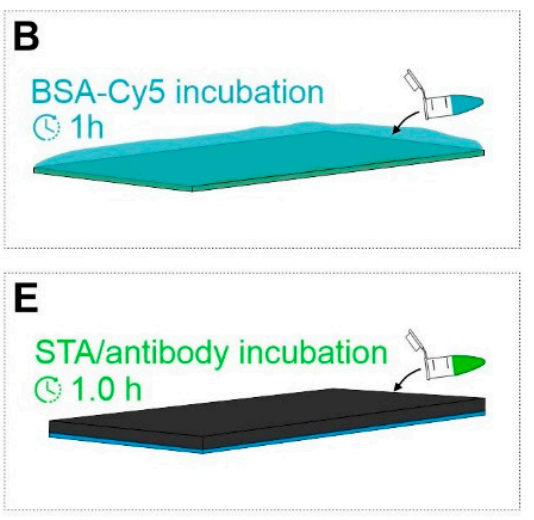



Figure 1. Schematic workflow of simplified large-area protein micropatterning on activated glass substrates. In short, untreated glass substrates are activated by coating with AnteoBind ${ }^{\mathrm{TM}}$ reagent (A). In parallel, a large-area PDMS stamp is incubated with BSA (or BSA-Cy5) solution for surface passivation (B). The stamp is subsequently placed onto the substrate, resulting in a transfer of the micron-scale BSA grid for surface passivation (C,D). After the stripping of the stamp, the patterned glass substrate is bonded with a 96-well plastic casting. Next, streptavidin and biotinylated antibodies are sequentially incubated (E). In a final step, cells are seeded onto the antibody-patterned surfaces for fluorescence microscopy analysis (F). Exemplary TIRF images of BSA-Cy5 printed surfaces with FITC-labeled antibody patterns (G). AFM image of micron-scale BSA grid and respective line profile. Scale bar $=3 \mu \mathrm{m}(\mathbf{H})$. 
A

\begin{tabular}{|c|c|c|c|c|c|c|}
\hline uncoated & $1: 10000$ & $1: 100$ & $1: 50$ & $1: 20$ & $1: 1$ & undiluted \\
\hline & & & & 1.2. & &  \\
\hline
\end{tabular}

B

concentration BSA $(\mathrm{mg} / \mathrm{mL})$

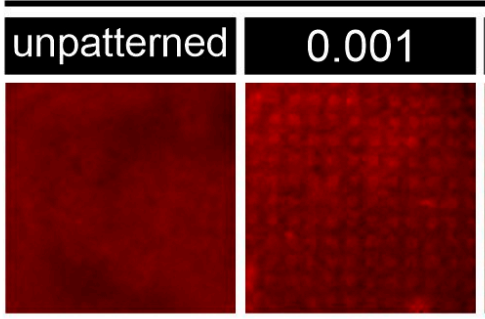

C

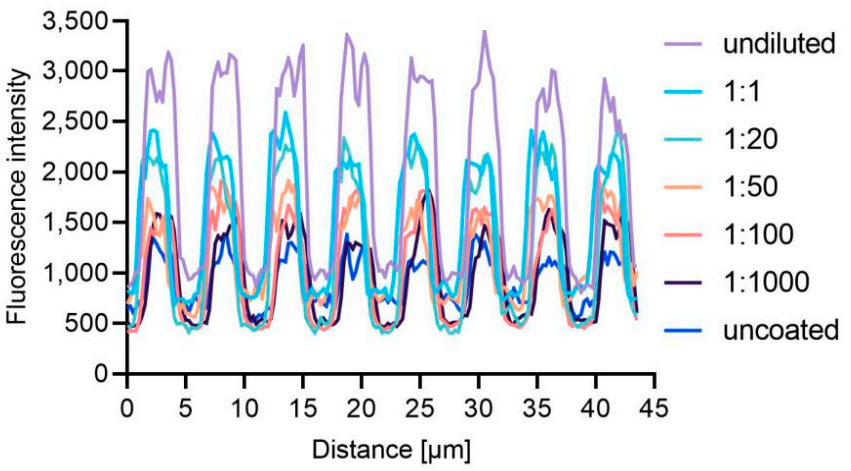

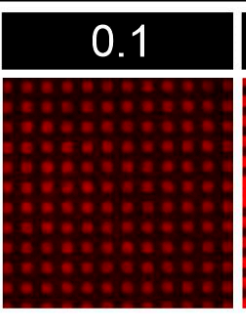
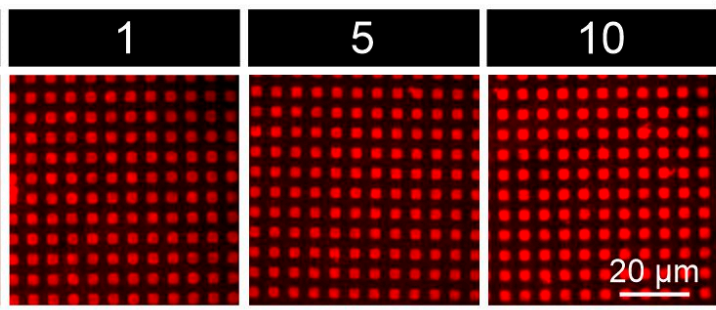

D



Figure 2. Characterization of AnteoBind ${ }^{\mathrm{TM}}$ coating for protein micropatterning via $\mu \mathrm{CP}$. (A) Glass substrates were precoated with indicated concentrations of AnteoBind ${ }^{\mathrm{TM}}$ reagent (diluted in $\mathrm{ddH}_{2} \mathrm{O}$ ) prior $\mu \mathrm{CP}$ with BSA-inked $(5 \mathrm{mg} / \mathrm{mL}$ ) PDMS stamps. BSA-patterned substrates were further modified with Cy5-labeled streptavidin $(50 \mu \mathrm{g} / \mathrm{mL})$. Binding of STA-Cy5 to uncoated glass surfaces was used as control. (B) Glass substrates were precoated with AnteoBind ${ }^{\mathrm{TM}}$ reagent $\left(1: 20\right.$ in $\left.\mathrm{ddH}_{2} \mathrm{O}\right)$ prior $\mu \mathrm{CP}$ with BSA-inked (indicated BSA concentrations) PDMS stamps. BSA-patterned substrates were further modified with Cy5-labeled strep(tavidin $(50 \mu \mathrm{g} / \mathrm{mL})$. Binding of STA-Cy5 to coated but unpatterned surfaces was used as control. (C) Representative line profiles of STA-Cy5 fluorescence signal at indicated AnteoBind ${ }^{\mathrm{TM}}$ dilution as shown in A. (D) Representative line profiles of STA-Cy5 fluorescence signal at indicated BSA concentration as shown in B.

Knowing the optimum surface coating dilution, we next investigated the impact of the surface passivation by printing a micron-scale BSA grid with varying concentrations (Figure 2B,D). In order to reduce specific costs for surface functionalization (which plays a major role, especially for the large substrates presented here), we picked the 1:20 dilution for surface coating. Figure 2B shows TIRF microscopy images of STA-Cy5-patterned glass surfaces that were precoated with 1:20 AnteoBind ${ }^{\mathrm{TM}}$ reagent concentrations and subsequently patterned with a BSA grid using concentrations between 0.001 and $10 \mathrm{mg} / \mathrm{mL}$ BSA. Representative line profiles of the respective STA-Cy5 signals are shown in Figure 2D. As a starting point, we chose $1 \mathrm{mg} / \mathrm{mL}$ BSA, which we and others have used for surface passivation on epoxysilane-coated glass slides and COP foils in previous studies $[36,53]$. Nevertheless, higher concentrations of BSA for improved surface passivation coatings 
have been recently reported $[54,55]$. Therefore, we increased the BSA amount for $\mu \mathrm{CP}$ up to $10 \mathrm{mg} / \mathrm{mL}$, which indeed resulted in the highest STA-Cy5 signal inside the active patterns (Figure 2D). A slightly lower pattern intensity was observed for 1 and $5 \mathrm{mg} / \mathrm{mL}$ BSA-printed surfaces, whereas, already, a tenfold lower concentration led to a substantial reduction in STA-Cy5 pattern enrichment. Almost no specific STA-Cy5 patterning could be detected for $0.001 \mathrm{mg} / \mathrm{mL}$ BSA passivated surfaces. Unpatterned, but AnteoBind ${ }^{\mathrm{TM}}$ reagent and BSA-coated surfaces were used as a control.

To further characterize the versatility of the implemented coating, we aimed in the printing of different proteins in addition to BSA. As shown in Figure S2, we were able to deposit various proteins (streptavidin, avidin, anti-EGFR IgG antibody, fibrinogen) onto the coated glass substrates by $\mu \mathrm{CP}$.

The general applicability of the AnteoBind ${ }^{\mathrm{TM}}$ reagent for immobilizing biomolecules, and more specifically antibodies, on various surfaces has been reported in several studies $[27,28,31,33]$. We could unequivocally show that this coating is also a superior and simple strategy for the surface activation, prior to $\mu \mathrm{CP}$ of proteins. Based on the intended application and pursued sensitivity of the assay, the reagent can be used in a wide concentration range, also in combination with common surface passivation steps.

\subsection{Applicability for Subcellular Micropatterning Experiments}

Finally, we demonstrated the applicability of AnteoBind ${ }^{\mathrm{TM}}$ reagent-coated and BSAstructured glass surfaces for subcellular micropatterning experiments in living cells. For this purpose, surfaces were further functionalized with streptavidin and anti-GFP antibodies and cells expressing a GFP-fused bait protein were grown on the antibody-patterned substrate. Upon specific antibody-antigen interaction, bait proteins will be rearranged in the plasma membrane according to the micron-scale antibody pattern (Figure 3A). To reduce fluorescence background signal, and to specifically visualize GFP-fused proteins within or near the cell membrane, the fluorescence readout was conducted in total internal reflection mode (TIRF microscopy). As a proof-of-concept bait, we overexpressed GFP-labeled ErbB2 (Erb-B2 receptor tyrosine kinase 2; GFP was fused to the extracellular domain of the receptor) in Hela cells. First, we elaborated on the specificity of bait patterning due to the antibody-antigen interaction (Figure 3B). For the quantitation of the lateral bait distribution, the respective fluorescence signal intensities within and outside the antibody-patterned areas were compared (mean fluorescence contrast $<\mathrm{c}>$ ) [41]. No rearrangement of GFP-ErbB2 was detected in cells grown on surfaces only functionalized with STA (Figure 3B,C, row $1 ;<\mathrm{c}\rangle=0.02 \pm 0.06$ ) and 'inert' anti-HA antibodies (Figure 3B,C, row $2 ;\langle\mathrm{C}\rangle=-0.02 \pm 0.04)$, respectively. On the contrary, a significant lateral redistribution of GFP-ErbB2 was detected in cells grown on anti-GFP antibody-patterned substrates (Figure 3B,C, row 3), resulting in a mean fluorescence contrast of $\langle\mathrm{C}\rangle=0.46 \pm 0.11$. This result again confirms robust surface protein patterning. Furthermore, the transfer of the micron-scale antibody pattern into the plasma membrane was only visible in cells facing functional and specific anti-bait antibodies.

As quantitative TIRF microscopy requires a flat interface between the plasma membrane and the patterned substrate to avoid false-positive signals and misinterpretation, we next checked the cell contact surface by coexpressing GFP-ErbB2 and RFP-Lact-C2 (RFP fused with C2 domain of bovine lactadherin) (Figure 3D). The inner-leaflet peripheral protein RFP-Lact-C2 turned out to be a good negative control, as it showed a homogenous membrane distribution in the central regions of GFP-ErbB2-patterned cells. Most importantly, the lack of RFP-Lact-C2 copatterning indicates that bait micropatterning has no measurable influence on plasma membrane curvature. 
A
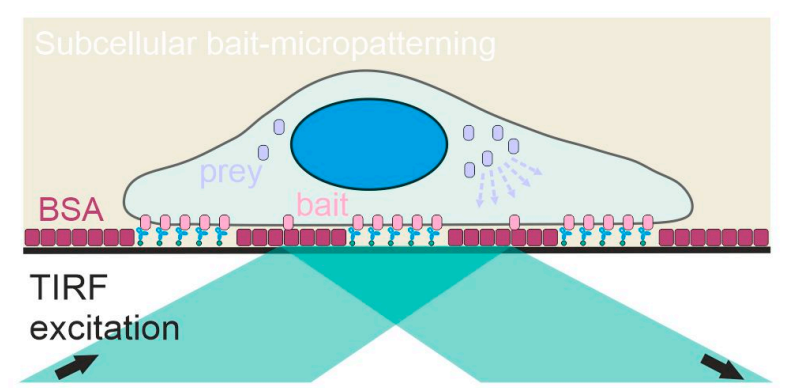

C

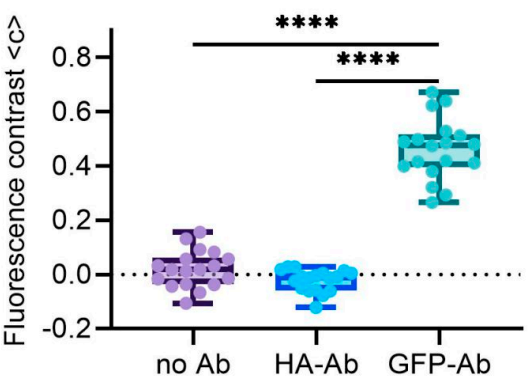

B


D
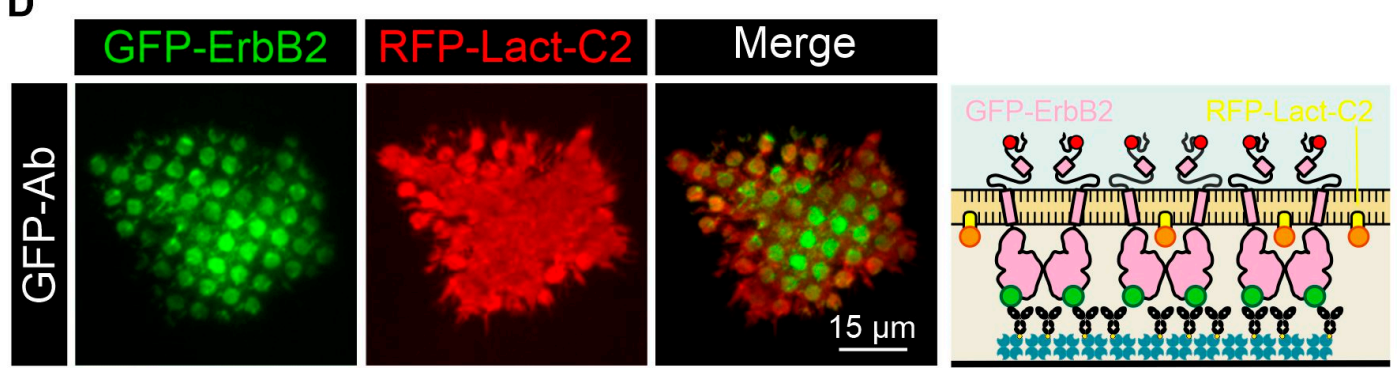

Figure 3. Applicability for subcellular micropatterning experiments. (A) Schematic presentation of the subcellular micropatterning assay. Cells are transiently cotransfected with fluorescently labeled bait (and prey) molecules and grown on antibody-patterned surfaces. Upon specific antibody-bait interactions, bait proteins are rearranged in the plasma membrane according to the surface pattern. (B) Representative TIRF microscopy images of GFP-ErbB2-expressing cells grown on BSA-Cy5-patterned surfaces consisting of: no antibodies (top), unspecific anti-HA antibodies (middle) and specific anti-GFP antibodies (bottom). (C) Box plots show quantitation of GFP contrast of cells grown under conditions as in (B) $\left(n=18\right.$ cells; ${ }^{* * *} p<0.0001$ for comparison with GFP-Ab). (D) Representative TIRF microscopy images of cells coexpressing GFP-ErbB2 and RFP-Lact-C2 grown on anti-GFP antibody-patterned surfaces. 
AnteoBind $^{\mathrm{TM}}$ reagent-coated surfaces have been reported to possess direct antibody binding capabilities with enhanced orientation and functionality, as the polymeric metal ions chelate to available electron-donating groups on synthetic surfaces and biomolecules [31]. We therefore investigated the bait-capturing capability of patterned surfaces that were directly functionalized with anti-GFP antibodies in comparison to surfaces comprising an additional STA layer prior to antibody addition (our "classical" way of antibody patterning) (Figure 4A,B). Indeed, we already found a remarkable GFP-ErbB2 enrichment in cells grown on solely antibody-functionalized substrates $(<c\rangle=0.33 \pm 0.10)$. Interestingly, antibody-induced GFP-ErbB2 patterning could be further enhanced by STA preincubation, resulting in a significantly increased fluorescence contrast value of $\langle c\rangle=0.53 \pm 0.12$. These results prove, again, the superior biomolecule-binding properties of this surface coating. Nevertheless, at least for the presented application, an additional streptavidin layer seems to be favorable for enhanced bait-capturing. Reasons for that might be diverse; however, it is fair to speculate that the covalent streptavidin-biotin interaction leads to a more optimized antibody orientation, also preserving its native character. Furthermore, an additional incubation of streptavidin might lead to a better accessibility of bound antibodies due to the compensation of possible differences in biomolecule heights present at the micropatterned glass surface.

A
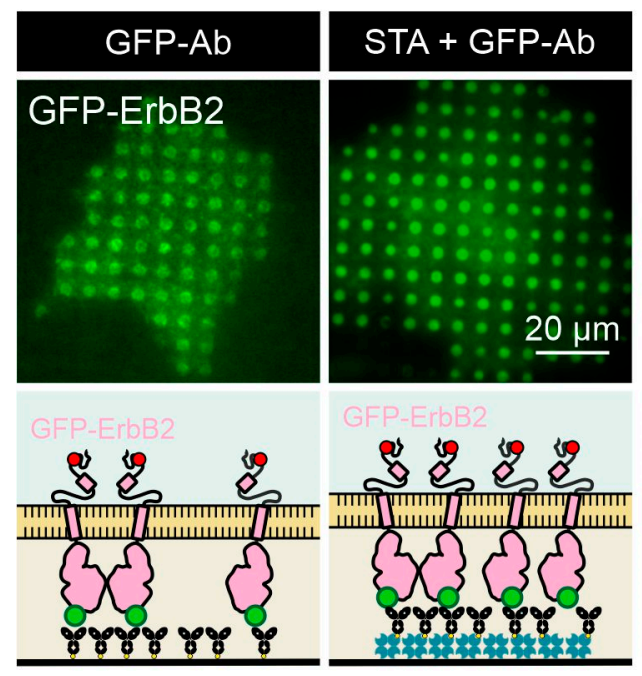

B
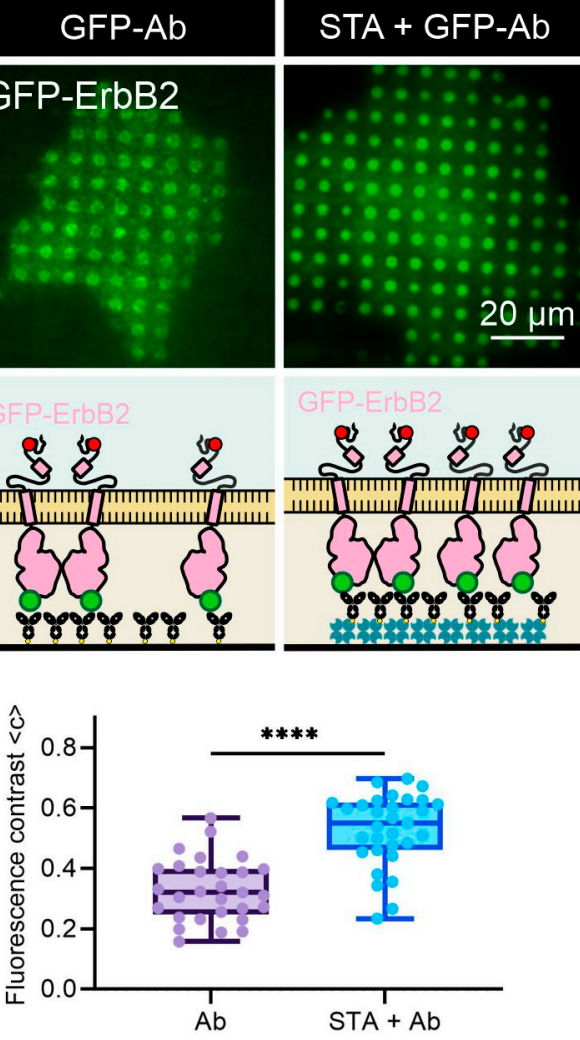

C
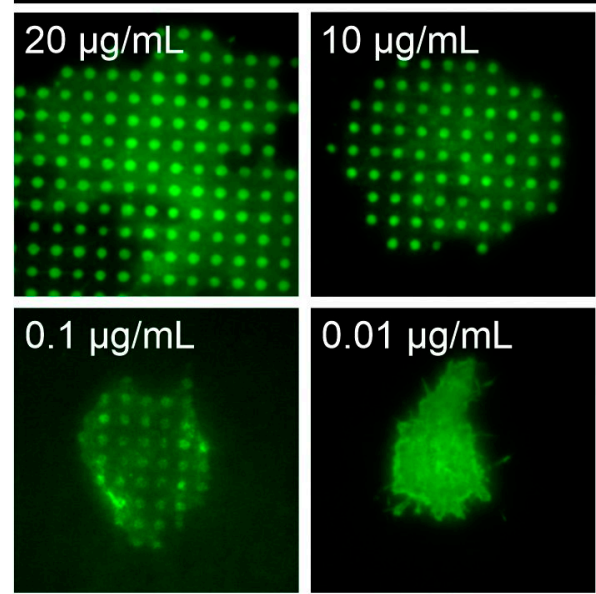

D



Figure 4. Evaluation of antibody specificity. (A) Representative TIRF microscopy images of GFPErbB2 expressing cells grown on solely anti-GFP antibody-patterned surfaces (left) and with an additional STA layer in between (right). (B) Box plots show quantitation of GFP contrast of cells grown under indicated conditions $\left(n>29\right.$ cells; ${ }^{* * *} p<0.0001$ for comparison of the two different conditions). (C) Representative TIRF microscopy images of GFP-ErbB2-expressing cells grown on surfaces bearing different concentrations of anti-GFP antibody. (D) Dot plot shows quantitation of antibody concentration-dependent mean GFP contrast ( $n=20$ cells per concentration). 
In a final step, we intended to work out optimum anti-bait antibody concentrations for live cell experiments (Figure 4C,D). Our standard working concentration, $10 \mu \mathrm{g} / \mathrm{mL}$, was also used in previous studies under similar conditions and throughout the presented experiments. We could recently show that this concentration leads to $>90 \%$ surface coverage within the pattern elements [43]. This might also explain the negligible increase in GFPErbB2 patterning when compared with higher antibody concentrations, such as $20 \mu \mathrm{g} / \mathrm{mL}$ $\left(<\mathrm{c}_{10}>=0.55 \pm 0.10\right.$ vs. $\left\langle\mathrm{c}_{20}>=0.59 \pm 0.12\right)$. Similar results were also obtained for tenfold lower antibody concentrations $\left(1 \mu \mathrm{g} / \mathrm{mL} ;\left\langle\mathrm{c}_{1}\right\rangle=0.49 \pm 0.14\right)$, whereas a clear drop in GFP-ErbB2 enrichment in antibody-patterned areas was obtained for $0.1 \mu \mathrm{g} / \mathrm{mL}$ $\left(<c_{0.1}>=0.19 \pm 0.07\right)$. No specific bait patterning was detected below concentrations of $0.01 \mu \mathrm{g} / \mathrm{mL}$ antibody.

\section{Conclusions}

In this study, we describe a simple and straightforward method to produce highly condensed protein micropatterned glass substrates via $\mu \mathrm{CP}$ without the need of initial extensive chemical surface activation and modification. The presented approach has no need for clean room facilities and/or expensive equipment. PDMS stamps carrying a micron-scale array of features of interest can be easily fabricated from pre-manufactured wafers or can be directly purchased from various companies. Once the stamps are established, they can be reused a couple of times and, with the appropriate wafer size, large-area $\mu \mathrm{CP}$ can be realized. Nevertheless, the introduced method can be flexibly adapted to almost any substrate size. Most importantly, untreated substrates (e.g., glass or polymers such as COP, COC, etc.) are very cheap and, based on our experience, the AnteoBind ${ }^{\mathrm{TM}}$ reagent can even be reused when recovered adequately after substrate incubation.

Altogether, this method represents a significant enhancement and simplification of existing $\mu \mathrm{CP}$ procedures and might further increase the accessibility of protein micropatterning for cellular biological research questions.

Supplementary Materials: The following supporting information can be downloaded at: https: / / www.mdpi.com/article/10.3390/bios12030140/s1: Figure S1: Simplified cross-section schemes of $\mu \mathrm{CP}$ procedure. Figure S2: $\mu \mathrm{CP}$ of different biomolecules.

Author Contributions: Conceptualization, P.L.; methodology, T.K., P.L. and J.W.; investigation, T.K., R.H., A.K. and P.L.; data curation, T.K., A.K. and P.L.; writing-original draft preparation, P.L.; writing-review and editing, T.K., J.W. and P.L.; visualization, A.K. and P.L.; supervision, P.L.; funding acquisition, J.W. and P.L. All authors have read and agreed to the published version of the manuscript.

Funding: This research was funded by the province of Upper Austria as part of the FH Upper Austria Center of Excellence for Technological Innovation in Medicine (TIMed CENTER), the Christian Doppler Forschungsgesellschaft (Josef Ressel Center for Phytogenic Drug Research), the Austrian Science Fund (FWF, project I4972-B), and the 'Dissertationsprogramm der Fachhochschule OÖ 2020' with the financial support of the province of Upper Austria (Austrian Research Promotion Agency (FFG) grant \#881300). It was also funded by a research project of the Austrian Competence Centre for Feed and Food Quality, Safety and Innovation (FFoQSI). The COMET-K1 Competence Centre FFoQSI is funded by the Austrian federal ministries BMK and BMDW and the Austrian provinces of Lower Austria, Upper Austria and Vienna within the scope of COMET-Competence Centers for Excellent Technologies. The COMET program is handled by the Austrian Research Promotion Agency FFG.

Institutional Review Board Statement: Not applicable.

Informed Consent Statement: Not applicable.

Data Availability Statement: The data presented in this study are available on request from the corresponding author.

Acknowledgments: The GFP-ErbB2 construct was a gift from Irene Tiemann-Boege (Johannes Kepler University Linz, Austria). mRFP-Lact-C2 was kindly provided by Sergio Grinstein (University of Toronto, Canada). Open Access Funding by the Austrian Science Fund (FWF). 
Conflicts of Interest: The authors declare no conflict of interest.

\section{References}

1. Wingren, C.; Borrebaeck, C.A.K. Progress in miniaturization of protein arrays-a step closer to high-density nanoarrays. Drug Discov. Today 2007, 12, 813-819. [CrossRef]

2. Chen, Z.; Oh, D.; Biswas, K.H.; Zaidel-Bar, R.; Groves, J.T. Probing the effect of clustering on EphA2 receptor signaling efficiency by subcellular control of ligand-receptor mobility. Elife 2021, 10, e67379. [CrossRef]

3. Lee, J.H.; Shao, S.; Kim, M.; Fernandes, S.M.; Brown, J.R.; Kam, L.C. Multi-Factor Clustering Incorporating Cell Motility Predicts T Cell Expansion Potential. Front. Cell Dev. Biol. 2021, 9, 648925. [CrossRef]

4. Mohr, J.D.; Ramezani, M.; Holowka, D.; Baird, B.A. Micropatterned Ligand Arrays to Investigate Spatial Regulation of Cellular Signaling Initiated by Clustered Fc Receptors. Methods Mol. Biol. 2022, 2421, 1-19. [CrossRef]

5. Mujahid, A.; Iqbal, N.; Afzal, A. Bioimprinting strategies: From soft lithography to biomimetic sensors and beyond. Biotechnol. Adv. 2013, 31, 1435-1447. [CrossRef]

6. Nguyen, A.T.; Sathe, S.R.; Yim, E.K.F. From nano to micro: Topographical scale and its impact on cell adhesion, morphology and contact guidance. J. Phys. Condens. Matter 2016, 28, 183001. [CrossRef]

7. Shemesh, M.; Lochte, S.; Piehler, J.; Schreiber, G. IFNAR1 and IFNAR2 play distinct roles in initiating type I interferon-induced JAK-STAT signaling and activating STATs. Sci. Signal. 2021, 14, eabe4627. [CrossRef]

8. Watson, J.L.; Aich, S.; Oller-Salvia, B.; Drabek, A.A.; Blacklow, S.C.; Chin, J.; Derivery, E. High-efficacy subcellular micropatterning of proteins using fibrinogen anchors. J. Cell Biol. 2021, 220, e202009063. [CrossRef]

9. Lenci, S.; Tedeschi, L.; Pieri, F.; Domenici, C. UV lithography-based protein patterning on silicon: Towards the integration of bioactive surfaces and CMOS electronics. Appl. Surf. Sci. 2011, 257, 8413-8419. [CrossRef]

10. Nicolau, D.V.; Ivanova, E.P.; Fulga, F.; Filipponi, L.; Viezzoli, A.; Dobroiu, S.; Alekseeva, Y.V.; Pham, D.K. Protein immobilisation on micro/nanostructures fabricated by laser microablation. Biosens. Bioelectron. 2010, 26, 1337-1345. [CrossRef]

11. Kristensen, S.H.; Pedersen, G.A.; Ogaki, R.; Bochenkov, V.; Nejsum, L.N.; Sutherland, D.S. Complex protein nanopatterns over large areas via colloidal lithography. Acta Biomater. 2013, 9, 6158-6168. [CrossRef] [PubMed]

12. Lohmüller, T.; Aydin, D.; Schwieder, M.; Morhard, C.; Louban, I.; Pacholski, C.; Spatz, J.P. Nanopatterning by block copolymer micelle nanolithography and bioinspired applications. Biointerphases 2011, 6, MR1-MR12. [CrossRef] [PubMed]

13. Hortigüela, V.; Larrañaga, E.; Cutrale, F.; Seriola, A.; García-Díaz, M.; Lagunas, A.; Andilla, J.; Loza-Alvarez, P.; Samitier, J.; Ojosnegros, S.; et al. Nanopatterns of Surface-Bound EphrinB1 Produce Multivalent Ligand-Receptor Interactions That Tune EphB2 Receptor Clustering. Nano Lett. 2018, 18, 629-637. [CrossRef] [PubMed]

14. Liu, H.-Y.; Kumar, R.; Takai, M.; Hirtz, M. Enhanced Stability of Lipid Structures by Dip-Pen Nanolithography on Block-Type MPC Copolymer. Molecules 2020, 25, 2768. [CrossRef]

15. Atwater, J.; Mattes, D.S.; Streit, B.; von Bojničić-Kninski, C.; Loeffler, F.F.; Breitling, F.; Fuchs, H.; Hirtz, M. Combinatorial Synthesis of Macromolecular Arrays by Microchannel Cantilever Spotting ( $\mu \mathrm{CS})$. Adv. Mater. 2018, 30, e1801632. [CrossRef]

16. Zheng, Z.; Daniel, W.L.; Giam, L.R.; Huo, F.; Senesi, A.J.; Zheng, G.; Mirkin, C.A. Multiplexed protein arrays enabled by polymer pen lithography: Addressing the inking challenge. Angew. Chem. Int. Ed. Engl. 2009, 48, 7626-7629. [CrossRef]

17. Alom Ruiz, S.; Chen, C.S. Microcontact printing: A tool to pattern. Soft Matter 2007, 3, 168-177. [CrossRef]

18. Berganza, E.; Hirtz, M. Direct-Write Patterning of Biomimetic Lipid Membranes In Situ with FluidFM. ACS Appl. Mater. Inter Faces 2021, 13, 50774-50784. [CrossRef]

19. Kaufmann, T.; Ravoo, B.J. Stamps, inks and substrates: Polymers in microcontact printing. Polym. Chem. 2010, 1, 371-387. [CrossRef]

20. Dias, A.D.; Kingsley, D.M.; Corr, D.T. Recent advances in bioprinting and applications for biosensing. Biosensors 2014, 4, 111-136. [CrossRef]

21. Humenik, M.; Winkler, A.; Scheibel, T. Patterning of protein-based materials. Biopolymers 2021, 112, e23412. [CrossRef] [PubMed]

22. Voskuhl, J.; Brinkmann, J.; Jonkheijm, P. Advances in contact printing technologies of carbohydrate, peptide and protein arrays. Curr. Opin. Chem. Biol. 2014, 18, 1-7. [CrossRef] [PubMed]

23. Zhou, X.; Boey, F.; Huo, F.; Huang, L.; Zhang, H. Chemically functionalized surface patterning. Small 2011, 7, 2273-2289. [CrossRef] [PubMed]

24. Guruvenket, S.; Rao, G.; Komath, M.; Raichur, A.M. Plasma surface modification of polystyrene and polyethylene. Appl. Surf. Sci. 2004, 236, 278-284. [CrossRef]

25. Kim, Y.-J.; Taniguchi, Y.; Murase, K.; Taguchi, Y.; Sugimura, H. Vacuum ultraviolet-induced surface modification of cyclo-olefin polymer substrates for photochemical activation bonding. Appl. Surf. Sci. 2009, 255, 3648-3654. [CrossRef]

26. Li, J.; Ji, S.; Zhang, G.; Guo, H. Surface-modification of poly(dimethylsiloxane) membrane with self-assembled monolayers for alcohol permselective pervaporation. Langmuir 2013, 29, 8093-8102. [CrossRef]

27. Lindner, M.; Tresztenyak, A.; Fülöp, G.; Jahr, W.; Prinz, A.; Prinz, I.; Danzl, J.G.; Schütz, G.J.; Sevcsik, E. A Fast and Simple Contact Printing Approach to Generate 2D Protein Nanopatterns. Front. Chem. 2018, 6, 655. [CrossRef]

28. Sánchez-Tirado, E.; Martínez-García, G.; González-Cortés, A.; Yáñez-Sedeño, P.; Pingarrón, J.M. Electrochemical immunosensor for sensitive determination of transforming growth factor (TGF)- $\beta 1$ in urine. Biosens. Bioelectron. 2017, 88, 9-14. [CrossRef] 
29. Sánchez-Tirado, E.; Salvo, C.; González-Cortés, A.; Yáñez-Sedeño, P.; Langa, F.; Pingarrón, J.M. Electrochemical immunosensor for simultaneous determination of interleukin-1 beta and tumor necrosis factor alpha in serum and saliva using dual screen printed electrodes modified with functionalized double-walled carbon nanotubes. Anal. Chim. Acta 2017, 959, 66-73. [CrossRef]

30. Ojeda, I.; Barrejón, M.; Arellano, L.M.; González-Cortés, A.; Yáñez-Sedeño, P.; Langa, F.; Pingarrón, J.M. Grafted-double walled carbon nanotubes as electrochemical platforms for immobilization of antibodies using a metallic-complex chelating polymer: Application to the determination of adiponectin cytokine in serum. Biosens. Bioelectron. 2015, 74, 24-29. [CrossRef]

31. Ooi, H.W.; Cooper, S.J.; Huang, C.-Y.; Jennins, D.; Chung, E.; Maeji, N.J.; Whittaker, A.K. Coordination complexes as molecular glue for immobilization of antibodies on cyclic olefin copolymer surfaces. Anal. Biochem. 2014, 456, 6-13. [CrossRef] [PubMed]

32. Martínez-García, G.; Sánchez-Tirado, E.; González-Cortés, A.; Yáñez-Sedeño, P.; Pingarrón, J.M. Amperometric immunoassay for the obesity biomarker amylin using a screen printed carbon electrode functionalized with an electropolymerized carboxylated polypyrrole. Mikrochim. Acta 2018, 185, 323. [CrossRef] [PubMed]

33. Hauser, P.; Wang, S.; Didenko, V.V. Apoptotic Bodies: Selective Detection in Extracellular Vesicles. Methods Mol. Biol. 2017, 1554, 193-200. [CrossRef]

34. Kim, S.; Kwak, S.; Lee, S.; Cho, W.K.; Lee, J.K.; Kang, S.M. One-step functionalization of zwitterionic poly(3-(methacryloylamino) propyl)dimethyl(3-sulfopropyl)ammonium hydroxide surfaces by metal-polyphenol coating. Chem. Commun. 2015, 51, 5340-5342. [CrossRef] [PubMed]

35. Yang, L.; Han, L.; Jia, L. A Novel Platelet-Repellent Polyphenolic Surface and Its Micropattern for Platelet Adhesion Detection. ACS Appl. Mater. Interfaces 2016, 8, 26570-26577. [CrossRef] [PubMed]

36. Hager, R.; Müller, U.; Ollinger, N.; Weghuber, J.; Lanzerstorfer, P. Subcellular Dynamic Immunopatterning of Cytosolic Protein Complexes on Microstructured Polymer Substrates. ACS Sens. 2021, 6, 4076-4088. [CrossRef] [PubMed]

37. Nečas, D.; Klapetek, P. Gwyddion: An open-source software for SPM data analysis. Open Phys. 2012, 10, 181-188. [CrossRef]

38. Borgmann, D.; Weghuber, J.; Schaller, S.; Jacak, J.; Winkler, S.M. Identification of patterns in microscopy images of biological samples using evolution strategies. In Proceedings of the European Modeling and Simulation Symposium, Vienna, Austria, 19-21 September 2012.

39. Lanzerstorfer, P.; Müller, U.; Gordiyenko, K.; Weghuber, J.; Niemeyer, C.M. Highly Modular Protein Micropatterning Sheds Light on the Role of Clathrin-Mediated Endocytosis for the Quantitative Analysis of Protein-Protein Interactions in Live Cells. Biomolecules 2020, 10, 540. [CrossRef]

40. Lanzerstorfer, P.; Borgmann, D.; Schütz, G.; Winkler, S.M.; Höglinger, O.; Weghuber, J. Quantification and kinetic analysis of Grb2-EGFR interaction on micro-patterned surfaces for the characterization of EGFR-modulating substances. PLoS ONE 2014, 9, e92151. [CrossRef]

41. Sevcsik, E.; Weghuber, J.; Lanzerstorfer, P.; Schütz, G.J. Protein Micropatterning Assay-Quantitative analysis of protein-protein interactions. Methods Mol. Biol. 2017, 1550, 261-270. [CrossRef]

42. Motsch, V.; Brameshuber, M.; Baumgart, F.; Schütz, G.J.; Sevcsik, E. A micropatterning platform for quantifying interaction kinetics between the T cell receptor and an intracellular binding protein. Sci. Rep. 2019, 9, 3288. [CrossRef] [PubMed]

43. Dirscherl, C.; Löchte, S.; Hein, Z.; Kopicki, J.-D.; Harders, A.R.; Linden, N.; Weghuber, J.; Garcia-Alai, M.; Uetrecht, C.; Zacharias, M.; et al. Dissociation of $\beta 2 \mathrm{~m}$ from MHC Class I Triggers Formation of Noncovalent, Transient Heavy Chain Dimers. bioRxiv 2021. [CrossRef]

44. Dirscherl, C.; Hein, Z.; Ramnarayan, V.R.; Jacob-Dolan, C.; Springer, S. A two-hybrid antibody micropattern assay reveals specific in cis interactions of MHC I heavy chains at the cell surface. Elife 2018, 7, e34150. [CrossRef] [PubMed]

45. Kam, L.C.; Shen, K.; Dustin, M.L. Micro- and nanoscale engineering of cell signaling. Annu. Rev. Biomed. Eng. 2013, 15, 305-326. [CrossRef] [PubMed]

46. Lanzerstorfer, P.; Yoneyama, Y.; Hakuno, F.; Müller, U.; Höglinger, O.; Takahashi, S.-I.; Weghuber, J. Analysis of insulin receptor substrate signaling dynamics on microstructured surfaces. FEBS J. 2015, 282, 987-1005. [CrossRef] [PubMed]

47. Sánchez, M.F.; Dietz, M.S.; Müller, U.; Weghuber, J.; Gatterdam, K.; Wieneke, R.; Heilemann, M.; Lanzerstorfer, P.; Tampé, R. Dynamic in situ confinement triggers ligand-free neuropeptide receptor signaling. bioRxiv 2021. [CrossRef]

48. LaGraff, J.R.; Chu-LaGraff, Q. Scanning force microscopy and fluorescence microscopy of microcontact printed antibodies and antibody fragments. Langmuir 2006, 22, 4685-4693. [CrossRef] [PubMed]

49. Graber, D.J.; Zieziulewicz, T.J.; Lawrence, D.A.; Shain, W.; Turner, J.N. Antigen Binding Specificity of Antibodies Patterned by Microcontact Printing. Langmuir 2003, 19, 5431-5434. [CrossRef]

50. Dirscherl, C.; Springer, S. Protein micropatterns printed on glass: Novel tools for protein-ligand binding assays in live cells. Eng. Life Sci. 2018, 18, 124-131. [CrossRef]

51. Nikolova, D.; Dayss, E.; Leps, G.; Wutzler, A. Surface modification of cycloolefinic copolymers for optimization of the adhesion to metals. Surf. Interface Anal. 2004, 36, 689-693. [CrossRef]

52. Mizutani, T. Estimation of protein and drug adsorption onto silicone-coated glass surfaces. J. Pharm. Sci. 1981, 70, 493-496. [CrossRef]

53. Schwarzenbacher, M.; Kaltenbrunner, M.; Brameshuber, M.; Hesch, C.; Paster, W.; Weghuber, J.; Heise, B.; Sonnleitner, A.; Stockinger, H.; Schütz, G.J. Micropatterning for quantitative analysis of protein-protein interactions in living cells. Nat. Methods 2008, 5, 1053-1060. [CrossRef] [PubMed] 
54. Ma, G.J.; Ferhan, A.R.; Jackman, J.A.; Cho, N.-J. Conformational flexibility of fatty acid-free bovine serum albumin proteins enables superior antifouling coatings. Commun. Mater. 2020, 1, 45. [CrossRef]

55. Park, J.H.; Jackman, J.A.; Ferhan, A.R.; Ma, G.J.; Yoon, B.K.; Cho, N.-J. Temperature-Induced Denaturation of BSA Protein Molecules for Improved Surface Passivation Coatings. ACS Appl. Mater. Interfaces 2018, 10, 32047-32057. [CrossRef] [PubMed] 